Las historiografías desarrollistas en Argentina. Consideraciones desde las producciones de Aldo Ferrer y Rogelio Frigerio

\title{
Las historiografías desarrollistas en Argentina. Consideraciones desde las producciones de Aldo Ferrer y Rogelio Frigerio ${ }^{1}$
}

\author{
The developmental historiographies in Argentina. Considerations \\ since the productions of Aldo Ferrer and Rogelio Frigerio
}

\author{
Federico Hernán Reche \\ Centro de Investigaciones María Saleme Burnichon, \\ Facultad de Filosofía y Humanidades, \\ Universidad Nacional de Córdoba; \\ Consejo Nacional de Investigaciones Científicas y Técnicas (Argentina) \\ rechefederico@gmail.com
}

\begin{abstract}
Resumen
En el presente trabajo realizamos un acercamiento crítico a las historiografías surgidas en Argentina de la mano de las ideas desarrollistas que tuvieron su incorporación, auge y desarrollo durante los años posteriores a la caída del peronismo. Específicamente, analizamos cómo los diagnósticos económico-políticos elaborados por dos importantes economistas argentinos -Aldo Ferrer y Rogelio Frigerio- fundamentan la tarea historiográfica que llevan a cabo con un explícito afán de intervención política. Así, como parte de sus intervenciones en el acalorado debate en torno a los modelos de desarrollo de aquellos años, realizaron aportes significativos a la historiografía económica nacional, aunque sus producciones se desarrollaron al margen, pero en dialogo con las de los historiadores renovadores profesionalizados. Sostenemos que la tesis del agotamiento del modelo de industrialización por sustitución de importaciones que formulan y la necesidad de justificar sus propuestas económico-políticas de desarrollo, constituyen el fundamento de sus empresas de producción historiográfica.
\end{abstract}

Palabras Clave

Desarrollismo; Historiografía económica; Industrialización; Tesis del agotamiento.

\section{Abstract}

\footnotetext{
${ }^{1}$ El presente artículo es parte de una investigación más amplia desarrollada bajo la dirección de Silvia Morón y Ruben Caro. Agradezco los comentarios y críticas que realizaron, a versiones previas de este trabajo, Claudio Belini y Damián Antúnez; por último, a los evaluadores propuestos por la revista que, sin duda, han contribuido a la mejora de este trabajo.
}

Esta obra está sujeta a la Licencia Reconocimiento-NoComercial-CompartirIgual 4.0 Internacional de Creative Commons. http://creativecommons.org/licenses/by-nc-sa/4.0/ 


\section{Federico Reche}

In this paper we realize a critical approach to the historiographies arisen in Argentina from the hand of the developmental ideas that had their incorporation, boom and development during the years after the fall of Peronism. Specifically, we analyze how the economicpolitical diagnoses elaborated by two important Argentine economists -Aldo Ferrer and Rogelio Frigerio- base the historiographic task that they carry out with an explicit eagerness of political intervention. Thus, as part of their interventions in the heated debate around the development models of those years, they made significant contributions to the national economic historiography, although their productions were developed on the margins, but in dialogue with those of the professionalized historians renewers. We maintain that the thesis of the exhaustion of the industrialization model by substitution of imports that they formulate and the need to justify their economic-political proposals of development, constitute the foundation of their companies of historiographic production.

\section{Keywords}

Development; Economic Historiography; Industrialization; Exhaustion thesis.

\section{Introducción}

En el marco de la complejización creciente del mapa historiográfico de los años '60, y como parte de las nuevas historiografías que pretendían ofrecer relatos más sintonizados con los tiempos que corrían (Devoto \& Pagano, 2010), algunos destacados economistas argentinos elaboraron reconstrucciones historiográficas apuntalando la conformación del campo de investigaciones del "desarrollo del subdesarrollo". Estas historiografías artífices de múltiples hermenéuticas del pasado -al igual que la historiografía de las izquierdas- se inscriben sin duda en el proceso de renovación historiográfica al que aportó no solo la naciente sociología científica, sino, además, la economía política con la que varios historiadores pretendían dialogar. La contribución que produjo a la renovación historiográfica el ensanchamiento de la economía en el país -de la mano de los debates sobre el desarrollo- implicó la influencia de nuevas perspectivas, autores y ámbitos institucionales que anudaban incluso aceitados vínculos internacionales.

Estas producciones historiografías elaboradas por un conjunto de intelectuales entre los que podemos destacar a Aldo Ferrer, Rogelio Frigerio, Guido Di Tella o Marcelo Diamand, y a las que en el presente artículo proponemos considerar como "historiografías desarrollistas", ponen de relieve los esfuerzos de reconstrucción histórica en los que se involucraron algunos de los más sobresalientes economistas de la época. Sin dudas, se presentaba con extremada fuerza una agenda política que moldeaba las miradas sobre el pasado y las proyectaba sobre la contemporaneidad, marcando estrategias, tareas y empresas (Rougier \& Odisio, 2017: 222 y ss.). Aun cuando sus producciones historiográficas constituyeron solo uno de los espacios o ámbitos donde se expresan sus visiones de mundo, la recepción de estas producciones por parte de los historiadores, y los debates acaecidos respecto de la aplicación de los modelos económicos construidos por las teorías del desarrollo y la 


\section{Las historiografías desarrollistas en Argentina. Consideraciones desde las producciones de Aldo Ferrer y Rogelio Frigerio}

modernización, dan cuenta de la relevancia de estas producciones que requieren ser indagadas en el marco de una historia de la historiografía económica argentina. El abordaje crítico de estas historiografías, contemporáneas e influyentes en el proceso de renovación, pero a la vez ajenas al campo de los historiadores renovadores profesionalizados, permite ponerlas de relieve en el acalorado debate en torno a los modelos de desarrollo para el país que se desenvolvía en esos años. Con este fin, en el presente artículo abordamos los análisis elaborados por Ferrer y Frigerio respecto de la situación económico-política de la Argentina de los años posperonistas, destacando que es sobre la base de estos diagnósticos y en la necesidad de fundamentar sus propuestas económicas de desarrollo, que llevan adelante su tarea historiográfica.

Así, con un explícito afán de intervención política y bajo la propuesta de profundizar la industrialización en curso, sus interpretaciones del proceso económico que justifican la tarea historiográfica comparten el diagnóstico del agotamiento del proceso de industrialización por sustitución de importaciones que se había desarrollado hasta esos años. Aunque de estas controversias participaron también acérrimos opositores a la industrialización e intelectuales marxistas que cuestionaron la capacidad de ésta para revertir los problemas económicos y sociales latinoamericanos, los primeros críticos de la ISI fueron los propios economistas preocupados por los problemas del desarrollo y fieles promotores de la industrialización latinoamericana: Ferrer y Frigerio, pero también Guido Di Tella y Marcelo Diamand entro otros (Bellini, 2017; Rougier \& Odisio, 2017)

Resulta a primera vista paradójico que intelectuales decididamente "proindustrialistas", como Ferrer y Frigerio, se refirieran al agotamiento de la sustitución de importaciones. Sin embargo, el hecho de que efectivamente lo que se ha dado en llamar la "tesis del agotamiento"2 pueda ser rastreada en las historiografías desarrollistas o incluso en autores como Prebisch o Furtado (Belini, 2017: 354 y ss.), obliga a una indagación respecto de los sentidos sociopolíticos que la tesis adquirió en aquellas particulares condiciones políticas y económicas. Esta

\footnotetext{
${ }^{2}$ La tesis del agotamiento porta una larga historia que nos permite encontrarla desde los años '60 hasta la década del '90 del siglo XX en un desenvolvimiento que implica cambios en los sentidos sociopolíticos de su enunciación y diversidad de supuestos teóricos. En efecto, variados autores de distintas tradiciones intelectuales, campos disciplinares y orientaciones político-ideológicas distintas puede ser asociados a esta idea. Una lista extensa, aunque no completa, de autores que han formulado y sostenido esta perspectiva, en diferentes contextos desde hace 50 años, incluiría a Aldo Ferrer, Marcelo Diamand, Rogelio Frigerio y Guido Di Tella, Raúl Prebisch o Celso Furtado, pero también a Oscar Braun o Juan Carlos Portantiero, y en una perspectiva disímil, gran parte de la literatura de orientación liberal. En efecto, por paradójico que resulte, en los años '60 y '70 participaron de la controversia sobre el desempeño de la ISI, decididos opositores a la industrialización e intelectuales marxistas que descreían de la viabilidad del desarrollo capitalista en la región. Luego de 1976, la reformulación y expansión de esta idea ha sido notable y ha desbordado disciplinas y perspectivas en las que se encontraba acotaba previamente. Con connotaciones y alcances notablemente diferentes algunos de sus variados promotores han sido José Nun y Juan Carlos Portantiero, Halperín Donghi, Juan Carlos De Pablo, Juan José Llach, Pablo Gerchunoff, Marcos Novaro, Vicente Palermo, Julio Cesar Neffa o Roberto Cortes Conde. Un desarrollo exhaustivo de las tesis del agotamiento y sus críticas puede consultarse en Reche (2015)
} 


\section{Federico Reche}

tarea, a la que se enfrenta nuestro trabajo busca aclarar los supuestos teóricos que constituyen el basamento de la "tesis del agotamiento" tal como se presentan en las producciones de Ferrer y Frigerio, y que permite diferenciarla de otras formas de esta tesis que surgirán con posterioridad.

\section{A propósito del desarrollismo argentino}

El desarrollismo como corriente política, ideológica o económica, e incluso como tendencia de análisis sociológico, adquirió una enorme complejidad en los países latinoamericanos. En ellos, a mediados de los años '50 cuajó como "un programa de compromiso elaborado dentro de una matriz de restricciones y oportunidades nacionales e internacionales" (Sikkink, 2009: 24), en el cual se cruzan tensiones y miradas respecto a las historias nacionales, las perspectivas económicas y los posicionamientos políticos, con aristas significativas en torno a la política interna y externa latinoamericana.

En Argentina, el término "desarrollismo" pone de manifiesto una diversidad de cuestiones distintas, que en ocasiones se tornan contradictorias si se decide observarlo desde un aspecto particular: la forma que adquirió el movimiento político denominado desarrollismo. Ciertamente, las programáticas de Frigerio, Ferrer, Di Tella o Diamand asumen una perspectiva desarrollista que busca un crecimiento económico y social de la comunidad observable cuantitativamente y que pretende la configuración de una sociedad con rasgos típicos y particulares de las naciones "desarrolladas" del norte occidental; en todos los casos, el progreso industrial resulta significativo a los efectos de advertir este "avance" social (Di Tella, Chumbita, Gajardo, \& Gamba, 2008). ${ }^{3}$

Que el término desarrollismo haya sintetizado una particular experiencia política en el marco nacional no debe restringir nuestra mirada respecto de las amplias formas en que las ideas de la economía del desarrollo surgieron, ingresaron y se extendieron en Argentina y América Latina. Siguiendo a Altamirano (2007), es posible pensar en un ciclo de debates intelectuales en torno a la idea de desarrollo iniciado con la "Revolución" de 1955, más específicamente a partir de la

\footnotetext{
3 Forcinito (2013), analizan algunos debates que Ferrer, Di Tella y Diamand tuvieron en relación con "la estrategia desarrollista", considerando a ésta como la promovida por la política del gobierno de Frondizi. Esta acepción del desarrollismo en sentido restringido y asociado a una experiencia de gestión económica, por de más usual en las ciencias sociales argentinas, acota la definición más amplia que estamos proponiendo. En efecto, la propia autora utiliza, cuando su mirada no está centrada exclusivamente en Argentina una referencia al desarrollismo en términos más precisos y generales. El desarrollismo implica, para Forcinito (2013: 91), el "consenso reformista del capitalismo que surgió como respuesta a la ausencia de crecimiento económico en conjunción con mejoras relativas en el nivel de vida de las clases subalternas, característico de la mayor parte del mundo capitalista hasta entonces". Este incluye una variedad de perspectivas y posiciones entre los que se encuentra, sin dudas, la CEPAL (Forcinito, 2016: 69). No podría ser de otra manera, ya que la formulación de la propia CEPAL constituye un impulso fundamental para la construcción del desarrollismo latinoamericano, que "en cada país (...) adquirió trazos singulares por las diferencias previas de formación económica y cultural” (Jáuregui, 2016: 2)
} 


\section{Las historiografías desarrollistas en Argentina. Consideraciones desde las producciones de Aldo Ferrer y Rogelio Frigerio}

presentación del informe preliminar conocido como Plan Prebisch. ${ }^{4}$ Estas polémicas deben ser abordadas intentando advertir la multiplicidad de perspectivas que desde el pensamiento económico tematizaron la idea de desarrollo en el país.

Al respecto, "[tanto] el informe Prebisch como su discusión posterior dejaron ver tempranamente varios de los temas en torno a los cuales se alinearían las posiciones en la escena pública" (Altamirano, 2007: 73). Este conjunto de tópicos, relativos a las tensiones entre "lo agrario" y "lo industrial", la función del Estado y el papel de la iniciativa privada y del capital extranjero, dominarán los debates intelectuales de los años siguientes. En este sentido, la idea de una época del desarrollismo permite liberarnos de la restricción que implica la conocida asociación del desarrollismo de manera exclusiva y excluyente con la propuesta y gobierno de Frondizi y Frigerio y, de esta forma, ampliar la búsqueda de explicaciones y sentidos en el conjunto amplio, pero específico, de debates económico-políticos que tuvieron lugar en esas circunstancias históricas. De otra manera: se trata de asumir que, aunque el desarrollismo "tuvo en la Argentina una evolución singular[, e]xistió aquello que denominamos desarrollismo genérico, transversal a muchos espacios políticos (radical popular, liberal tecnocrático o militar autoritario) y que en términos generales coincidía con las postulaciones de la CEPAL" (Jáuregui, 2016: 3). ${ }^{5}$

Este "consenso epocal" en relación con las características de la industrialización y la necesidad de superar las dificultades profundizándola, por distintas vías y con diferentes estrategias (Rougier y Odisio, 2017) tuvo origen cuando la caída del peronismo reinstaló el debate público sobre la dirección que debía tomar el capitalismo argentino (Llach, 1984). En aquel polémico documento, el propio jefe de la CEPAL afirmaba: "la Argentina atraviesa por la crisis más aguda de su desarrollo económico" (Prebisch, 1955: 11). Fuera de las discrepancias y polémicas específicas que se desarrollaron alrededor de la argumentación del informe preliminar, difícilmente se pueda negar la profundidad con que caló el argumento de la existencia de una insondable crisis económica en el país.

Sin la intransigencia del planteo de Prebisch, que no daba lugar a dudas respecto de los daños hechos por la política económica peronista, la idea de una crisis de dimensiones sin precedentes se instalaba para plantear la necesidad de un

\footnotetext{
${ }^{4}$ En verdad, el llamado Plan Prebisch fue el resultado de una serie de tres documentos distintos que se publicaron entre fines de 1955 y comienzos de 1956. Los tres documentos - "Informe preliminar acerca de la situación económica" (1955), "Moneda sana o inflación incontenible" (1956a) y "Plan de restablecimiento económico" (1956b) - fueron publicados por la Secretaría de Prensa de la Presidencia de la Nación. El Plan sufrió fortísimas críticas y los focos más relevantes fueron "la influencia del anti-peronismo de Prebisch en el evidente pesimismo del diagnóstico y el contraste de las sugerencias de política económica con las ideas pregonadas por Prebisch desde la CEPAL" (Fiszbein, 2010: s/p).

${ }^{5}$ Sobre las diferencias entre el desarrollismo cepalino y frigerista, que no profundizaremos aquí, puede consultarse García Bossio (2013) y Forcinito (2013). Jáuregui (2016: 3) plantea, luego de mencionar algunas diferencias centrales entre estas perspectivas, que "de todas maneras había más coincidencias de las que le gustaba reconocer. Ellas provenían de la inscripción genérica en la "economía del desarrollo" y por ende en el keynesianismo. En su concepción, el progreso histórico sólo podía alcanzarse a través del avance de la ciencia y de la técnica".
} 


\section{Federico Reche}

redireccionamiento de la política económica argentina. Esta marca de origen permanecerá como una constante de los discursos desarrollistas de la época, que asumieron una novedosa dramatización en el ámbito público. Definidos como elementos centrales de la vida política nacional, "las reformas que exigía el desarrollo no sólo eran necesarias, eran impostergables y acuciantes, su cumplimiento apenas si dejaba ya tiempo" (Altamirano, 2007: 76-77).

Las perspectivas desarrollistas presentaron además como singularidad, la pretensión de rediscutir la caracterización de la economía argentina en el marco de las tipificaciones sobre el desarrollo que habían comenzado a surgir en aquellos años. Especificar la posición del país en torno al eje desarrollo-subdesarrollo se constituirá en parte de la polémica. Tanto si observamos hacia adentro como si dirigimos la mirada al exterior del desarrollismo, la querella por el carácter subdesarrollado o no, por el nivel o "grado" de subdesarrollo e incluso por la explicación de las razones del subdesarrollo del país, inspirará investigaciones, intervenciones y reflexiones de diversa índole.

Las múltiples interpretaciones en disputa de la realidad económica motivaron así reconstrucciones historiográficas de la economía argentina que buscaban justificar la comprensión de un presente conflictivo y un futuro promisorio para el desarrollo industrial nacional. Devoto \& Pagano (2010) han comentado la recepción de estas producciones de economistas por parte de los historiadores profesionalizados, y los debates acaecidos respecto de la aplicación de los modelos económicos construidos por las teorías del desarrollo y la modernización implicadas. Así, plantean que "la colaboración en el terreno de la historia económica encontraba cultores de las dos disciplinas. Entre los economistas, dos autores destacaron por el énfasis que pusieron en reconstruir el pasado económico argentino: Guido Di Tella y Aldo Ferrer" (Devoto \& Pagano, 2010: 418). Y aunque según su perspectiva los economistas fueron "bastante poco influyentes entre los historiadores salvo como objetivo polémico", para nosotros su importancia parece notable cuando observamos la forma en que estas y otras reconstrucciones históricas realizadas por economistas de la época fueron retomadas en el marco de la renovación historiográfica en curso.

El carácter "militante", en el sentido planteado por Devoto \& Pagano (2004) ${ }^{6}$, de estas producciones historiográficas ajenas al campo de los historiadores profesionalizados, parece caracterizarse por la existencia de un eje articulador de los discursos programáticos de los intelectuales desarrollistas que se sitúa en la urgencia y necesidad de profundizar la industrialización de la economía argentina, dando respuesta a los problemas que hasta allí había tenido el desarrollo argentino.

\footnotetext{
${ }^{6}$ Si bien toda operación historiográfica posee un carácter decididamente político, Devoto \& Pagano (2004; 2010) llaman "historiografías militantes" a un conjunto de producciones elaboradas en ocasiones en los márgenes del ámbito académico, por intelectuales que no se desempeñan como historiadores profesionalizados y en las que el afán de intervención política de las producciones cristaliza en un particular vinculo pasado-presente.
} 


\section{Las historiografías desarrollistas en Argentina. Consideraciones desde las producciones de Aldo Ferrer y Rogelio Frigerio}

Así, la firmeza con que se asume el diagnóstico compartido respecto del agotamiento de la estrategia de industrialización por sustitución de importaciones desarrollada durante los gobiernos peronista constituye la base sobre la que se funda la necesidad de reorientar de la política económica. A partir de las propuestas formuladas y como ejercicio de comprensión del denominado agotamiento, es que se elaboraron reconstrucciones históricas que justificaban el diagnóstico y orientaban la interpretación sobre los problemas y soluciones que requería la economía argentina.

\section{Rogelio Frigerio: desarrollo industrial y capital extranjero}

Frigerio, promotor desde el Semanario Qué de la candidatura presidencial de Frondizi, será el teórico de la política impulsada por éste en el gobierno (Rouquié, 1975; Altamirano, 1998). Formulará una perspectiva en la que se asocia patriotismo a industrialismo y, desde el profundo reconocimiento del desarrollo producido bajo el peronismo, pretenderá distinguirse de la estrategia de desarrollo peronista a partir del convencimiento de que es necesario observar y profundizar la producción, antes que la distribución.

Un documento significativo en este sentido es Desarrollo y desarrollismo (1969), obra colectiva en la que destacan los nombres de Alonso Aguilar y Rogelio Frigerio, ${ }^{7}$ en el que los autores se encuentran embarcados en descifrar los elementos estructurales de las recurrentes crisis provenientes del estrangulamiento externo y proponer estrategias tendientes a su necesaria superación. En este marco se presenta la idea de agotamiento del proceso sustitutivo como diagnóstico de la difícil situación económica que es necesario revertir, ${ }^{8}$ reimpulsando el desarrollo nacional por medio de nuevas estrategias que profundicen la industrialización. Según se destaca en la introducción a cargo de Aguilar (1969), "[l]os años de euforia que acompañaron a la segunda guerra mundial han quedado definitivamente atrás" (13). Significativamente todos los índices marcan un comprobable estancamiento relativo que, sin menosprecio de los datos positivos de 1963-64, caracterizan la economía latinoamericana y dan cuenta de la fortaleza de los obstáculos al desarrollo presentes en la región (Aguilar, 1969).

Sin embargo, frente a los límites estructurales que plantea el subdesarrollo, Frigerio descree de la propuesta de Prebisch basada en la cooperación externa y los acuerdos logrados en el ámbito del comercio internacional ${ }^{9}$ que solo apelan a la buena

\footnotetext{
7Sobre Frigerio, puede consultarse el capítulo VI de Rouquié (1975); también, García Bossio (2008) y Jáuregui, Cerra y Yazbek, (2015).

8 También en un texto posterior Frigerio (1979) afirma, para comenzar a analizar el período iniciado en 1955, que "el agotamiento del impulso dado al país por el proceso de sustitución de importaciones gravitó en el deterioro de la situación social y política" (103).

${ }^{9}$ Se refiere a la política promovida desde la Conferencia de las Naciones Unidas sobre Comercio y Desarrollo -UNCTAD, por su nombre en inglés-. Esta línea de trabajo impulsada por Prebisch coincide con los años que estamos abordando en el análisis de las reflexiones de nuestros autores.
} 


\section{Federico Reche}

voluntad de las naciones desarrolladas para que, por distintos mecanismos comerciales y compensatorios, devuelvan, "derramen", parte de esa "plusvalía del comercio" (Frigerio, 1969: 133) a los países subdesarrollados. Si bien la aportación de las potencias no era voluntaria, en su opinión, sí existía la necesidad histórica, el devenir ineluctable de una competencia económica -de los bloques en pugna que se habían dividido el mundo en áreas de control e influencia- por la cual les resultaba necesario estimular al desarrollo de los países subdesarrollados (Altamirano, 2007). La salida propuesta por Frigerio no resulta tan importante como su defensa basada en la idea de que una nueva estrategia es necesaria en la medida que Argentina es un país "detenido en su crecimiento" (Frigerio, 1969: 115). Así, en la discusión en torno a la pertenencia a la categoría de países desarrollados o subdesarrollados, su opinión radica en que Argentina no se ubica entre el global de los países subdesarrollados ni entre los países industriales que figuran como potencias mundiales (Aguilar, 1969). Pero esta coincidencia de diagnóstico con otros desarrollistas tales como Di Tella o Ferrer no nos permite hacerlos avanzar juntos mucho más. Sus diferencias son notables y no solo sus textos se encuentran llenos de críticas de unos a otros, sino que el análisis de los elementos estructurales de la economía argentina y sus propuestas de política resultantes son verdaderamente opuestas. Las críticas y contraposiciones cruzadas son notables y los autores parecen esforzarse en expresar el grado de originalidad y, por supuesto, certeza de sus programáticas.

Para Frigerio, la clave para el desarrollo era sin lugar a duda la industrialización del país, pero esta tenía un significado de totalidad y completitud respecto de las actividades y ramas, y de integralidad territorial y espacial. Se pretendía una industrialización general que conformara un espacio económico integrado, física y culturalmente. Por esto, y como parte de las discrepancias entre los intelectuales desarrollistas, para Di Tella (1973) el esquema teórico del frondizismo hace la máxima "combinación de los inconvenientes del esquema clásico y del esquema autárquico" (38) en la medida que infiere la necesidad de desarrollar todas las industrias -con la consecuente reducción de la eficiencia general de la economía- y asume la gran dependencia del capital extranjero. Esta habitual crítica al esquema frigerista se encuentra justificada en la profundización de las industrias capital intensivas que tensionan aún más la necesaria utilización "armoniosa" de los factores.

Pero, según la opinión de Frigerio (1969), lo que define indefectiblemente el subdesarrollo es la incapacidad de un país de generar "los recursos necesarios para un crecimiento sostenido de la economía nacional" (119). Esta incapacidad de financiar el desarrollo con el producto de las exportaciones se encuentra en el corazón de su idea de subdesarrollo (Frigerio, 1968; 1979), de manera que el financiamiento exterior del progreso industrial resulta crucial (Frigerio, 1959). La noción de subdesarrollo así formulada por el desarrollismo frigerista, parece intentar suplantar discursivamente, según Rouquié (1975: 111) la oposición de clase: "la oposición nueva es la oposición entre desarrollo y subdesarrollo"; quienes 


\section{Las historiografías desarrollistas en Argentina. Consideraciones desde las producciones de Aldo Ferrer y Rogelio Frigerio}

quieren el desarrollo son revolucionarios y para conseguirlo es necesaria la unidad nacional. La justicia social de la sociedad de la abundancia vendrá como corolario del crecimiento, que la transformará por medio de una verdadera revolución industrial en los países subdesarrollados. Así, es posible convertir a Argentina en una gran potencia que aporte a la pretendida integración y concepción del mundo como comunidad.

En su acalorado discurso, el desarrollo parece remplazar al progreso (Altamirano, 2007) y pretender una marcha ininterrumpida de Argentina y la humanidad (Rouquié, 1975) de la mano del capitalismo. En términos de la economía política del desarrollo, la perspectiva frondizista no dudaba que las fuerzas sociales de la transformación que se proponía llevar adelante radicaban en los trabajadores y empresarios. En la programática del "desarrollismo argentino" era necesario entonces una alianza nacional-popular. En este sentido, la posibilidad de fundar un nuevo modelo de desarrollo económico no puede desconocer al conjunto de los actores opuestos a los intereses de la oligarquía agroexportadora; ${ }^{10}$ y los sectores ligados al nacional-industrialismo que deberían formar parte de esta alianza son, para Frigerio, el ejército, la iglesia y los sindicatos. De aquí, puede comprenderse que la alianza con los sectores peronistas se encuentra fundada en las "circunstancias", en la coincidencia respecto de la lectura histórica del desarrollo nacional y el juego de fuerzas sociales y políticas que ponen a cualquier proyecto que pretenda redireccionar el modelo sustitutivo, profundizando la industrialización en detrimento de los intereses de los "enemigos históricos" del peronismo.

Este elemento, que había aparecido ya antes del triunfo electoral de Frondizi, resulta una continuidad en el pensamiento de Frigerio. El fervor industrialista une históricamente a una diversidad de actores sociales y económicos que sigue resultando central aglutinar alrededor de una perspectiva clara y coherente. Esta promoverá la liberación nacional como resultado de la completitud de la transformación económica requerida que a su vez logrará romper la dependencia, ${ }^{11}$ cristalizada en la sistemática necesidad de divisas para financiar el aparato productivo del país.

En la estrategia desarrollista de Frigerio se reserva, por supuesto, un lugar central al Estado que debe garantizar la política de desarrollo por medio del mantenimiento del proteccionismo, la garantía a la libre empresa y la atracción de capitales extranjeros. Con ellos se irá formando un "capitalismo nacional”, un neocapitalismo

\footnotetext{
${ }^{10}$ El nacionalismo económico identifica como enemigos internos a los sectores con intereses "agroimportadores”. Véase Frigerio (1963), Franco (1969) y Rouquié (1975).

${ }^{11}$ Conviene advertir que el uso de ciertas expresiones, por caso "dependencia” o "liberación nacional" no tiene, evidentemente, el mismo significado con que leemos, generalizando, que fueron planteadas en ese tiempo. Probablemente ciertas preferencias por temas, debates y perspectivas recuperadas por la historiografía simplifican la variedad de significaciones que determinados vocablos del lenguaje político tuvieron. En este caso, las expresiones mencionadas aparecen en Frigerio como parte de un universo discursivo con significaciones muy fuertes, aunque diferentes a las que estamos acostumbrados a reconocer.
} 


\section{Federico Reche}

social y moderno fundado en una industria técnicamente avanzada. Sin embargo, el papel del Estado en la articulación y el mantenimiento de la política de desarrollo se distancia de la planificación socialista en boga, por la "decisión” de no realizar el ahorro sobre los grandes sacrificios de los trabajadores (Frigerio, 1963).

En todo caso, el Estado desarrollista debía ser el cerebro, el agente del desarrollo, que como Estado programador definiera las prioridades con arreglo a la meta de alcanzar el desarrollo pleno de la Nación. Sin embargo, esto no hacía perder importancia a la iniciativa privada, sino que pregonaba el requerimiento de la inversión y/o incorporación de capitales que ayudarían a profundizar, acelerar y garantizar el desarrollo industrial que -caso contrario- continuaría estancado $\mathrm{u}$ operando en niveles cercanos al estancamiento.

Esta colaboración del capital extranjero asumirá cada vez mayor relevancia y urgencia a medida que los ensayos y experiencias de la larga década se vean frustrados en su capacidad de garantizar el crecimiento económico y la estabilidad política. Esta aportación resultará nodal para conseguir mayor independencia económica toda vez que se vincula estrechamente con la efectiva posesión de una industria pesada de envergadura que ha pasado a formar parte del núcleo básico de los objetivos nacionales.

Sin dudas, debe tenerse en cuenta que estamos aquí frente a otro punto de disidencia respecto de la perspectiva cepalina a la que considera "conformista" o "vagamente industrialista" por aceptar la financiación lenta y gradual del desarrollo. La opinión del cofundador del Movimiento de Integración y Desarrollo -MID-, opuestamente, tiende a considerar la urgencia de la transformación que, para realizarse vertiginosamente, requeriría de una inyección de capital que no resulta posible adquirir por la buena voluntad de otros gobiernos o de organismos internacionales. Inicialmente, el "modelo frondizista" propone compatibilizar desarrollo y democracia, y esta unión constituye un rasgo distintivo de su propuesta (Frigerio, 1963). Pero la correspondencia del desarrollo con la democracia, que habían sostenido en su etapa de gobierno, será abandonada luego de los reiterados fracasos entre 1955-66 y la disociación entre estos dos términos implicará que la democracia deje de figurarse como condición política del desarrollo (Forcinito, 2013: 91). Esto explica que Frondizi no se negara a apoyar la vía autoritaria del Onganiato cuando los regímenes semidemocráticos de la época parecieron incapaces de garantizar la sostenibilidad de la estrategia desarrollista.

Y en verdad, cuando llegó la alternativa de la modernización por vía autoritaria a mediados de los años sesenta, el desarrollismo se dispuso a explorar lo que sería uno de sus últimos intentos serios. Con el golpe de Estado de 1966,

"la idea de un gran cambio, es decir no de un simple golpe de Estado, que pusiera a la nación por encima de sus facciones, se fijó así en el horizonte de una sociedad bloqueada entre fuerzas que no podían vencer ni acordar principios comunes acerca de cómo gobernarse". (Altamirano, 2007: 108). 


\section{Las historiografías desarrollistas en Argentina. Consideraciones desde las producciones de Aldo Ferrer y Rogelio Frigerio}

El notable fracaso de esta alterativa afectó la forma en que el desarrollismo fue interpelado en adelante. A partir de entonces, los debates se polarizarán de otra manera con relación a la posibilidad del desarrollo, en términos políticos específicos nacionales, y en términos económicos y teóricos generales. El intento frustrado de la Revolución Argentina, evidente desde 1969, radicalizará las críticas: los desarrollistas, se fortalecerán en la idea de la necesidad de un redireccionamiento estratégico de la política económica que lograra empujar hacia adelante a un país que parecía definitivamente estancado; los sectores liberales continuarán negando con más fuerza la mutación de la idea de progreso por la de desarrollo en que no dejaba de insistir el país; y, también bajo la crítica marxista al desarrollismo que se estaba produciendo en el contexto regional, sectores detractores asumirán la impugnación de un régimen económico y político que, a sus ojos, no lograba consolidarse y sobrevivía a los tumbos en una situación de crisis permanente.

Afrontar esa crisis cada vez más aguda, proponer alternativas para profundizar la industrialización y encontrar las razones del agotamiento constituyeron razones mas que suficientes para encarar reconstrucciones historiográficas como las realizadas por Frigerio (1969; 1979). Estas "historias económicas" constituían además armas de combate en un presente de disputa, incluso al interior del desarrollismo.

\section{Aldo Ferrer: nacionalismo y estructuralismo}

La perspectiva de Ferrer se encuentra articulada en algunos textos fundamentales de su profusa obra entre los cuales se destaca La economía argentina (1963) ${ }^{12}$ que es quizás uno de los libros más visitados de historia económica argentina (Fernández López, 2001). ${ }^{13}$ En él, Ferrer asume la tarea de elaborar un cuadro general del proceso formativo de la economía de manera que sintetiza los rasgos característicos y las formaciones estructurantes que en cada momento -desde el siglo XVI hasta la actualidad- definen sus notas distintivas y problemas contemporáneos. La definición de etapas históricas que ordenan su trabajo responde al planteo realizado por Celso Furtado (1962) para el caso de la economía brasileña. La suposición que aparece como base del esfuerzo es que, tal como había propuesto el método histórico-estructural de la Comisión Económica para América

\footnotetext{
${ }^{12}$ Si bien la versión original del texto es de 1963, bajo el mismo nombre fue publicada en 1973 una edición actualizada en la que se modificó la cuarta parte el libro y se agregó una quinta incorporando los desarrollos más recientes y lo acontecido en esa década, que es de nuestro especial interés. Entre una y otra emerge el debate sobre el agotamiento del modelo ISI. Así, a pesar de que el texto que ha sido reeditado un sinnúmero de veces hasta la actualidad, hemos utilizado la versión correspondiente a al texto revisado y ampliado de 1973.

${ }^{13}$ La secuencia se completa con Crisis y alternativas de política económica en Argentina (1977), Nacionalismo y orden constitucional (1983), El capitalismo argentino (1998) y Vivir con lo nuestro (2012).
} 


\section{Federico Reche}

Latina (CEPAL), ${ }^{14}$ la descripción del proceso de desarrollo a partir de las definidas etapas históricas que se remontan hasta los "orígenes" de las formaciones sociales analizadas, permite "penetrar en profundidad en el análisis de las causas de la situación presente y ver como se fueron desenvolviendo con el correr del tiempo hasta llegar a la actualidad" (Ferrer, 2000 [1973]: 13).

En la base de su motivación para realizar este análisis de las "raíces históricas" de la situación de que es contemporáneo, se encuentra -por supuesto, al igual que en Frigerio- la intención de proponer una estrategia de desarrollo que permita superar la crítica situación que surge de sus evaluaciones. En su análisis se presenta una reivindicación de las capacidades y potencialidades nacionales para lograr un desarrollo acelerado y autosuficiente, característico de los países "desarrollados", aunque paradójicamente se evidencia que el país habría sido incapaz de realizar a tiempo los ajustes necesarios para adaptarse a las condiciones y características del desarrollo histórico contemporáneo. Así, de las cuatro etapas perfectamente diferenciables para la mirada del autor, el profundo análisis de la cuarta, inaugurada en 1930 y definida por el carácter semi-industrial dependiente ${ }^{15}$ de la economía, permite llegar a "la conclusión de que el sistema ha entrado en una crisis definitiva que frena su posterior evolución y crecimiento" (Ferrer, 2000 [1973]: 14-15).

Al mismo tiempo que se produce este diagnóstico, el autor destaca la intención de elaborar propuestas que permitan salir de la situación de estancamiento económico que vive el país. Así lo afirma cuando escribe:

"frente a esta crisis de desarrollo, procuro identificar los distintos rumbos alternativos que procuran las fuerzas sociales operantes en la realidad argentina. Sostengo, además, la tesis de que el crecimiento futuro de la economía nacional y la elevación de los patrones de vida, materiales y culturales, de la población solo puede ser logrado mediante la integración de la estructura económica, esto es, la formación de una economía industrial avanzada." (Ferrer, 2000 [1973]: 15).

Frente a su diagnóstico de crisis de desarrollo, la salida se encuentra en reorientar el proceso de desarrollo, para ayudar a la maduración económica. El diagnóstico del agotamiento $^{16}$ de aquella etapa histórica, que es al mismo tiempo un modelo a los

\footnotetext{
${ }^{14} \mathrm{Al}$ respecto véase Pinto (1970).

15 Esta se caracteriza centralmente por la presencia de una estructura económica y social diversificada, comparable a las economías avanzadas. Sin embargo, prevalece una insuficiente integración de las fases de la producción manufacturera, junto a los altos precios relativos de los bienes industriales -como rasgo distintivo del carácter semi-industrial- y a la "inmadurez del desarrollo" alcanzado. Mas adelante, tendremos oportunidad de profundizar la caracterización de la etapa post-1930. Por cierto, el nombre y caracterización de esta etapa varia en las diferentes versiones (previas y posteriores) de su libro. Estas son expresivas de momentos intelectuales signados, tanto por preocupaciones y debates diferentes, como por desplazamientos del autor. Al respecto véase Forcinito (2016: 116).

${ }^{16}$ En un trabajo reciente Forcinito (2016: 136) destaca que Ferrer no plantea el agotamiento de la estrategia sustitutiva de importaciones hacia los años sesenta. Sin embargo, sus afirmaciones se
} 


\section{Las historiografías desarrollistas en Argentina. Consideraciones desde las producciones de Aldo Ferrer y Rogelio Frigerio}

fines de la interpretación, supone la existencia de un freno al crecimiento de la economía nacional pero no niega la posibilidad de la continuidad del desarrollo industrial. Su intención declarada es entonces señalar las condiciones y establecer las bases para un nuevo modelo y etapa del desarrollo social. Sin lugar a duda, la explícita influencia de Furtado encuentra rápidamente su límite en este punto y Ferrer se mantiene más cercano al optimismo de Prebisch, su antiguo maestro. ${ }^{17}$

Sin embargo, al igual que en el planteo de Furtado el agotamiento se expresa en la tendencia secular a la baja de la tasa de crecimiento per cápita, las recurrentes crisis cíclicas y las altas tasas de desempleo. De esta manera la argumentación de Ferrer coincide tanto en el enfoque histórico-estructural como en la manera de dar cuenta del "agotamiento", que para ambos se evidencia en las pobres tasas de crecimiento del producto per cápita y las recurrentes restricciones externas (Ferrer, 2000 [1973]; Furtado, 1962). Pese a esto, no encontramos puntos en común tan importantes al momento de exponer las causas del agotamiento, ni al analizar las características estructurales y orgánicas de las sociedades dependientes. Más allá de las evidentes diferencias entre el modelo brasileño y la particular configuración de la economía argentina -que ya el mismo trabajo del brasilero había dejado fuera de su análisis-, es notable la diferencia dada por la clave política a ambas exposiciones. El término dependencia en Ferrer parece presentarse solamente a los fines de identificar una economía no integrada o avanzada, es decir, como oposición a la estructuración socioeconómica de los países desarrollados. Este juego de oposición resulta más una continuidad de la endíadis centro-periferia cepalina que de la construcción dependentista de la que Ferrer es contemporáneo. ${ }^{18}$ En este sentido, la clave política de lectura de Ferrer -compartida con otros desarrollistas argentinos- lo distancia del pesimismo de Furtado. En el economista argentino, el análisis del agotamiento está signado por la positividad provista a la formulación de una estrategia de desarrollo que permita continuar el proceso de industrialización y consolide un camino de crecimiento autónomo, que jamás se duda posible.

\footnotetext{
encuentran dirigidas a distinguir el planteo de Ferrer respecto del neoestructuralismo latinoamericano. En esta reelaboración de la CEPAL, liderada por Fanjzylber, se presenta la tesis del agotamiento desde supuestos y con significaciones realmente distintas a las presentes en el desarrollismo argentino de los fines de los años ‘60 y '70. Además, la dureza con que se desarrollan las críticas a la ISI varía en las diferentes versiones del texto analizado y de la producción de Ferrer en general. En efecto, cuando la tesis del agotamiento se expanda y tienda a justificar el abandono de la política de industrialización, en los últimos años '70, Ferrer se convertirá en un claro polemista de esta idea.

17 Sobre el vínculo de Ferrer con Prebisch puede consultarse Fernández López (2001) y García Bossio (2013).

18 Reforzando lo planteado en la nota 9, quisiéramos remarcar a fin de evitar confusiones que el término dependencia se propagó más rápidamente en los estudios latinoamericanos que la concepción propuesta como clave de relectura de las sociedades latinoamericanas por los dependentistas. Así, aparecerá un sinnúmero de veces a los fines de indicar exclusiva y excluyentemente la condición periférica de un país; despojado, aunque interpretado variadamente, del carácter que le otorga la formulación de la crítica más radical al desarrollo capitalista latinoamericano.
} 


\section{Federico Reche}

Retomando el análisis de las etapas históricas propuestas por Ferrer, al momento de concentrarse sobre aquella que se encuentra en crisis en su presente histórico, enfatiza que para la comprensión de los principales cambios en la dinámica del sistema económico se requiere de una precisa descripción que permita advertir los puntos de saturación y colisión entre fenómenos de carácter estructural que tienen presencia en la economía semi-industrial dependiente argentina. Centralmente, se pueden distinguir la modificación en el comportamiento de la demanda global, el proceso de sustitución de importaciones, la estructura y dinámica industrial y agropecuaria y el papel desempeñado por el Estado.

La inspección de estos cambios permite distinguir dos subperíodos al interior de la etapa iniciada con la crisis de 1929. Según su propia expresión: "conviene destacar dos subperíodos dentro de las últimas cuatro décadas, o sea, a partir de la clausura de la etapa primaria exportadora". El primero abarca desde 1930 hasta fines de la década de 1950, “...dentro de este primer subperíodo se consuma en la argentina el proceso sustitutivo de importaciones en la industria tradicional y la mecánica y química livianas. El segundo subperíodo desde 1950 hasta la actualidad", en que los hechos más importantes son "la profundización del proceso de industrialización y el surgimiento de obstáculos crecientes a la formación de una economía industrial avanzada" (Ferrer, 2000 [1973]: 192).

En realidad, la periodización surge justificada por la dinámica de las transformaciones internacionales que reconoce dos unidades distinguibles hasta y desde la segunda posguerra. Pero rápidamente queda imbricada con la dinámica interna en un criterio suficientemente economicista como para dejar dividido en dos a la experiencia del peronismo histórico y resaltar el carácter de continuidad que adquiere su primera etapa, de claro crecimiento, de una segunda etapa vinculada al momento en que comienza la crisis que se ubicaría "cerca de 1950". Posteriormente, este corte pasará a la historiografía con fecha 1949. Una precisión destacable que se justifica por medio de un "dato relevante" que da cuenta del agotamiento del proceso $^{19}$ sustitutivo $^{20}$ : la disminución del coeficiente de importaciones. Esta disminución había sido importante desde los años veinte y para 1949 el coeficiente

\footnotetext{
${ }^{19}$ Destacamos proceso sustitutivo de importaciones en el marco de las distinciones formuladas por Reche (2019). De acuerdo con lo planteado por el autor es posible identificar la existencia de al menos tres sentidos o usos habituales de la expresión Industrialización por Sustitución de Importaciones. El primero de ellos refiere a una práctica económico-productiva; el segundo, a un período histórico de la economía nacional; el tercero, a una programática económico-política como estrategia de desarrollo. La mención a un agotamiento del "proceso sustitutivo" referiría, según nuestra interpretación, a la primera de estas acepciones.

${ }^{20}$ Según apunta Ferrer (2000 [1973]) la sustitución de importaciones no es un proceso estático que refiere exclusivamente a la "producción interna de una determinada cantidad de bienes anteriormente importados (...) sino que abarca dinámicamente la satisfacción de la mayor y cambiante demanda que se va creando como consecuencia del desarrollo" (182) vinculado la expansión del ingreso y el progreso técnico. En su carácter profundamente transformador, que amplía y modifica la demanda, el proceso sustitutivo se obliga a sí mismo a continuar. ¿Hasta qué punto?
} 


\section{Las historiografías desarrollistas en Argentina. Consideraciones desde las producciones de Aldo Ferrer y Rogelio Frigerio}

se encontraba en torno a 10\%. A partir de 1950, se estabilizará y mantendrá este nivel durante el período siguiente.

Según la opinión de Ferrer, aunque es evidente que esta fuerte reducción generó inconvenientes en el proceso de acumulación de capital,

"la economía de divisas generada por la sustitución de importaciones permitió enfrentar la declinante capacidad de pagos externos. A partir de 1950, en cambio, la estabilización del coeficiente de importaciones vinculó estrechamente el crecimiento de la actividad productiva al nivel de los abastecimientos importados" (Ferrer, 2000 [1973]: 195)

dando lugar al surgimiento de desequilibrios crónicos de la balanza de pagos.

En el momento que el coeficiente de importaciones se ha reducido lo suficiente y se estabiliza, la sustitución se ha frenado de hecho como proceso. Es que la clave se encuentra en que, antes de llegar a la autarquía económica, se desencadena una crisis difícil de resolver por la complejidad de la estructuración económica que ha ido apareciendo a partir de las profundas mutaciones que implica el propio desarrollo industrial. De esta forma, la imposibilidad de integración dada por el desfasaje entre el avance manufacturero y el progreso técnico, que se produjo en las industrializaciones "clásicas", abandona al país a una situación de semiindustrialización.

Aunque la sustitución de importaciones -en los países de desarrollo industrial tardío como Argentina- involucra un proceso clave para adecuar la estructura de la producción, aumentar el ingreso y modernizar el sistema productivo haciendo un uso más eficaz del trabajo, "no se consuma en la autarquía, sino que entra en crisis mucho antes" (Ferrer, 2000 [1973]: 201). Tanto es así que "la compresión del coeficiente de importaciones más allá de ciertos límites ... se paga en términos de desarrollo económico" (184). Nuevamente se presenta el corte que el autor identifica, además, como modificatorio de la política económica ${ }^{21}$ y de la evolución del ingreso nacional. ${ }^{22}$

Finalmente, la alternativa propuesta frente al diagnóstico elaborado busca continuar y profundizar el desarrollo económico por medio de la industrialización y

\footnotetext{
21 No nos involucraremos aquí con el campo referido a las políticas económicas, aunque es interesante señalar que Ferrer advierte como coincidencia que alrededor del punto de corte se establece un cambio también en la política económica; esta fluctuará a partir de ese momento entre las inspiradas por perspectivas más liberales o más desarrollistas. Esta "alternancia" es destacada con fuerza en todas las perspectivas desarrollistas y llega a su formulación mas explicita con la idea del péndulo de Diamand.

22 Al igual que otras interpretaciones con gran presencia en el pensamiento económico latinoamericano, respecto del crecimiento del producto, resulta significativo el peso otorgado al hecho de cómo este tiende a estancarse en relación con el aumento de la población. Según Ferrer (2000 [1973]), "el aumento de la producción a partir de 1948 apenas ha alcanzado para compensar el incremento de la población del país y las condiciones de vida de amplias capas sociales no ha experimentado ningún avance o, aún más, se han deteriorado" (11).
} 


\section{Federico Reche}

la modificación del patrón y composición de exportaciones, garantizando la participación creciente de los sectores que están liderando el desarrollo. Solo promoviendo esta atención a las manufacturas será posible avanzar en la integración productiva y la formación de una economía avanzada (Ferrer, 2000 [1973]; 1983). Pero revertir el perfil de inserción internacional del país resulta una consecuencia de una serie de transformaciones que deben ser producidas a partir de un programa de movilización del potencial interno que articule "la utilización del ahorro interno, la ruptura del estrangulamiento del balance de pagos, la política de cambio tecnológico y la integración territorial" (Ferrer, 2000 [1973]: 274). La posibilidad de caminar en esta dirección supone una serie de condiciones que necesariamente se deben cumplir. Estas revelan la trascendencia otorgada por el autor a la dimensión sociopolítica en la evaluación y planificación del desarrollo. Sin la "nacionalización" y democratización del Estado, la "argentinización" de la estructura productiva, la reforma de la organización productiva y la asunción del poder político por las mayorías -combatiendo la ideología dependiente de las minorías hegemónicas- no será posible articular ningún programa de desarrollo económico y social en Argentina.

Respecto de la condición de subdesarrollo y la posibilidad de despegue económico, el economista sostiene que el país se encuentra en un lugar relevante y con potencial suficiente para revertir su dependencia. Así, comparte el entusiasmo con Frigerio, Di Tella y Diamand, pero diferenciándose al considerar al subdesarrollo como resultado de elementos estructurales del complejo sistema económico mundial. De acuerdo con la opinión de Ferrer (2000 [1973]), Argentina cuenta con recursos, diversificación de la oferta, capacidad productiva y una extensión territorial y de mercado interno que le permite distinguirse de la mayoría de los otros países latinoamericanos dependientes. En este sentido, urge revertir la crisis que se está experimentando ya que, aunque "no implique una fractura inminente, reflejada en la alteración de las relaciones sociales subyacentes" (267), el modelo vigente "frustra la movilización del enorme potencial económico argentino, genera fracturas en las estructuras productivas y entre grupos sociales, profundiza los desequilibrios espaciales y articula una relación dependiente frente al resto del mundo" (268).

\section{Notas Finales}

El contexto de crisis que implicó el fracaso del Plan Krieger Vassena (1967-1969) habilitó una nueva etapa en el pensamiento desarrollista en la cual se profundizó el pesimismo respecto de los problemas del desarrollo argentino y se multiplicó el diseño de estrategias alternativas que pretendían superar dicha situación sobre la base de la idea de que la economía argentina experimentaba un verdadero agotamiento del modelo ISI. Las producciones de Ferrer y Frigerio analizadas en este trabajo, posteriores a 1969, resultan reveladoras y expresivas de los debates de "época" en que emergió la diagnostico del agotamiento. Los "economistas", que habían adquirido ya desde hacía algunos años una palabra privilegiada en el debate 


\section{Las historiografías desarrollistas en Argentina. Consideraciones desde las producciones de Aldo Ferrer y Rogelio Frigerio}

nacional (Plotkin \& Neiburg 2014), redoblaron sus esfuerzos por construir explicaciones de los fenómenos que vivía la turbulenta Argentina de aquellos días. ${ }^{23}$ Justificar las razones del agotamiento y proponer alternativas que profundicen la industrialización en curso motivó a los desarrollistas argentinos a elaborar reconstrucciones historiográficas en las que se plasmaron múltiples hermenéuticas del pasado. Estas reconstrucciones a las que hemos denominado "historiografías desarrollistas" comparten con las historiografías de las izquierdas que emergieron por aquellos mismos años un explicito afán de intervención política y una rica producción realizada, en ocasiones, desde los márgenes de la historiografía académica.

Los autores que abordamos en este texto han insistido en sus esfuerzos intelectuales por dar cuenta del lugar, entre distintivo y excepcional, de Argentina en el concierto de países. Mientras para Frigerio, Argentina devendría indefectiblemente en potencia económica a partir de la inversión extranjera, para Ferrer la posibilidad del desarrollo radicaba en la integración de los factores económicos del país. Para reevaluar los objetivos nacionales que deben siempre sustentar la estrategia de desarrollo a partir de una clara conciencia de las potencialidades y limitaciones, era necesario advertir correctamente el punto de inicio, así como el posible rol en el concierto internacional. Con este fin es que se vuelve necesario, para Ferrer y para Frigerio partir de una evaluación y un diagnóstico certero sobre las condiciones para el desarrollo, tal como este se ha configurado históricamente. Así, la necesidad que motiva la tarea historiográfica que llevan a cabo estos intelectuales ubicados en el exterior del campo de la historiografía profesionalizada, tienen la pretensión de lograr un reconocimiento de sus propuestas para superar el agotamiento de la ISI que ellos mismos advierten; cada vez con mas fuerza mientras se suceden los fracasos políticos de aquellos críticos años.

La posición distintiva de Argentina respecto de las naciones sumidas en la pobreza y el estancamiento habilita un ejercicio de doble distinción y autorreconocimiento que constituye un elemento decisivo en la singularización del pensamiento desarrollista. Como hemos mostrado en este trabajo, el diagnostico pesimista desde el que se formula la tesis del agotamiento parte de la evaluación que realizan de la economía de su presente y del análisis histórico que, a la luz de este, formulan del proceso de industrialización sustitutiva.

Así, aunque el diagnóstico del agotamiento aparezca sin dudas tempranamente en estas producciones su intencionalidad difiere de las tesis formuladas años después tanto por quienes se declaraban acérrimos opositores a la industrialización

23 Véase Rapoport (2013), donde se presentan los principales debates económico-políticos argentinos; además, el autor esboza breves biografías y apretadas síntesis de las interpretaciones de algunos de los más importantes economistas argentinos. Por su parte, en Navarro (2007), y con motivo del $50^{\circ}$ aniversario de la Asociación Argentina de Economía Política, se puede encontrar un importante repaso por los desarrollos de la teoría económica en Argentina, los avances metodológicos y las producciones historiográficas más relevantes. En Neiburg \& Plotkin (2004), las referencias son más generales, ya que abarca a las ciencias sociales en general. 


\section{Federico Reche}

argentina como por aquellos que encontraban inviable pensar el desarrollo al interior de la dinámica de industrialización que el capitalismo global de la segunda posguerra había "habilitado" en los países latinoamericanos. En los desarrollistas argentinos, y especialmente al interior de sus producciones historiográficas, la tesis del agotamiento del modelo de industrialización por sustitución de importaciones al que desde su labor demarcan por primera vez- intenta poner sobre el debate los nuevos modelos de industrialización que cada uno de ellos propone. Las diferencias en la propuesta programática de los autores, produce, en una proyección hacia el pasado, jerarquizaciones de los fenómenos y problemas económicos donde esas diferencias terminan por expresarse. La tesis del agotamiento del modelo sustitutivo, tal como es planteada por los desarrollistas argentinos aparece como un diagnóstico que condiciona la política económica, en tanto la obliga a repensarse y reimpulsarse, pero en absoluto reclama la existencia de límites estructurales a la posibilidad del desarrollo económico y social de la nación.

\section{Bibliografía}

Aguilar, A. (1969). Refutación a las teorías sobre subdesarrollo. En A. Aguilar y R. Frigerio (eds.); Desarrollo y desarrollismo. Buenos Aires: Galerna.

Altamirano, C. (1998). Los nombres del poder. Arturo Frondizi. Buenos Aires: Fondo de Cultura Económica.

Altamirano, C. (ed.) (2007). Bajo el signo de las masas (1943-1973) (Vol. 6). Buenos Aires: Emecé.

Belini, C. (2017). Historia de la industria en la Argentina: de la Independencia a la crisis de 2001. Buenos Aires: Sudamericana.

Devoto, F. \& Pagano, N. (2004). La historiografía académica y la historiografía militante en Argentina y Uruguay. Editorial Biblos.

Devoto, F. \& Pagano, N. (2010). Historia de la historiografía argentina. Buenos Aires: Sudamericana.

Di Tella, G. (1973). La Estrategia del Desarrollo Indirecto. Buenos Aires: Paidós.

Di Tella, T., Chumbita, H., Gajardo, P. \& Gamba, S. (coords.) (2008). Diccionario de ciencias sociales y políticas. Buenos Aires: Emecé. 


\section{Las historiografías desarrollistas en Argentina. Consideraciones desde las producciones de Aldo Ferrer y Rogelio Frigerio}

Fernández López, M. (2001). La Ciencia Económica Argentina en el Siglo XX. En AAEP, Anales de la Asociación Argentina de Economía Política. Buenos Aires: Asociación Argentina de Economía Política.

Ferrer, A. ([1973] 2000). La economía argentina. México: Fondo de Cultura Económica.

Ferrer, A. (1977). Crisis y alternativas de la política económica argentina. Buenos Aires: Fondo de Cultura Económica.

Ferrer, A. (1983). Nacionalismo y orden constitucional: respuesta a la crisis económica de la Argentina contemporánea. Buenos Aires: Fondo de Cultura Económica.

Ferrer, A. (1998). El capitalismo argentino. Buenos Aires: Fondo de Cultura Económica.

Ferrer, A. (2009). Vivir con lo nuestro. Buenos Aires: Fondo de Cultura Económica.

Fiszbein, M. (2010). Instituciones e ideas en desarrollo. La planificación económica en la Argentina, 1945-1975. En M. Rougier (ed.); Estudios sobre la industria argentina. Políticas de promoción y estrategias empresariales. Buenos Aires: Lenguaje Claro.

Franco, J. P. (1969). Reflexiones en torno al desarrollismo: el caso frigerista. En A. Aguilar, A. \& R. Frigerio (eds.); Desarrollo y desarrollismo. Buenos Aires: Galerna.

Frigerio, R. (1959). Las condiciones de la victoria. Buenos Aires: Sociedad Editora Argentina.

Frigerio, R. (1963). Crecimiento económico y democracia. Buenos Aires: Losada.

Frigerio, R. (1968). La integración regional instrumento del monopolio. Buenos Aires: Editorial Hernández.

Frigerio, R. (1969). El carácter de la crisis crónica de la economía argentina y la estrategia para superarla. En A. Aguilar \& R. Frigerio (Eds.) Desarrollo y desarrollismo. Buenos Aires: Galerna.

Frigerio, R. (1979). Síntesis de la Historia Crítica de la economía argentina (desde la conquista hasta nuestros días). Buenos Aires: Hachette. 


\section{Federico Reche}

Forcinito, K. (2013). La estrategia del desarrollismo en la Argentina. Debates y aportes. Realidad Económica, (274), pp. 89-107.

Forcinito, K. (2016). La historiografía estructuralista y neoliberal sobre la economía argentina: balance crítico y controversias (Tesis de Doctorado inédita). Doctorado en Economía. Universidad Nacional de Rosario.

Furtado, C. (1962). Formación económica del Brasil. México: Fondo de Cultura Económica.

García Bossio, H. (2008). Génesis del Estado desarrollista latinoamericano: el pensamiento y la praxis política de Helio Jaguaribe (Brasil) y de Rogelio Frigerio (Argentina). Documentos de Trabajo, (23).

García Bossio, H. (2013). Desarrollismo cepalino vs. desarrollismo frigerista: la Junta de Planificación Económica de la Provincia de Buenos Aires en la experiencia argentina (1958-1962). Temas de Historia Argentina y Americana, (21), pp. 15-37.

Jáuregui, A. (2016). Desarrollismo y el progreso en la Argentina: un aporte marxista. Trabajos y Comunicaciones, (44), pp. 1-17. Recuperado de http://www.memoria.fahce.unlp.edu.ar/art_revistas/pr.7505/pr.7505.pd

Jáuregui, A., Cerra, Á., \& Yazbek, S. (eds.) (2015). Génesis y construcción del desarrollismo argentino. Buenos Aires: Editorial Biblos

Llach, J. J. (1984). El Plan Pinedo de 1940, su significado histórico y los orígenes de la economía política del peronismo. Desarrollo Económico, 23 (92), 515-558.

Navarro, A. M. (2007). Medio siglo de economía. Conmemorativo del $50^{\circ}$ aniversario de la Asociación Argentina de Economía Política. Buenos Aires: Temas.

Neiburg, F. \& Plotkin, M. (2004). Intelectuales y expertos: la constitución del conocimiento social en la Argentina. Buenos Aires: Paidós.

Pinto, A. (1970) Prefacio. En A. de Castro \& C. Lessa, Introducción a la economía (un enfoque estructuralista). Buenos Aires: Siglo XXI.

Plotkin, M. \& Neiburg, F. (2014). Elites intelectuales y ciencias sociales en la Argentina de los años 60. El Instituto Torcuato Di Tella y la Nueva Economía. Estudios Interdisciplinarios de América Latina y el Caribe, 14 (1), s/p.

Prebisch, R. (1955). Informe preliminar acerca de la situación económica. Buenos Aires: Secretaría de Prensa y Actividades Culturales de la Presidencia de la Nación. 


\section{Las historiografías desarrollistas en Argentina. Consideraciones desde las producciones de Aldo Ferrer y Rogelio Frigerio}

Prebisch, R. (1956a). Moneda sana o inflación incontenible. Buenos Aires: Secretaría de Prensa y Actividades Culturales de la Presidencia de la Nación.

Prebisch, R. (1956b). Plan de restablecimiento económico. Buenos Aires: Secretaría de Prensa y Actividades Culturales de la Presidencia de la Nación.

Reche, F. (2015). Debates intelectuales en la historia económica argentina: una historia de la tesis del agotamiento del Modelo de Industrialización por Sustitución de Importaciones (Tesis de Licenciatura en Historia inédita). Escuela de Historia, FFyHUNC, Córdoba.

Reche, F. (2019). La Industrialización por Sustitución de Importaciones (ISI): usos y sentidos de una expresión polisémica. Folia Histórica del Nordeste, 35.

Rougier, M. \& Odisio, J. (2017). "Argentina será industrial o no cumplirá sus destinos": las ideas sobre el desarrollo nacional (1914-1980). Buenos Aires: Ediciones Imago Mundi.

Rouquié, A. (1975). Radicales y desarrollistas en la Argentina. Buenos Aires: Schapire.

Sikkink K. (2009). El proyecto desarrollista en Argentina y Brasil. México: Siglo XXI.

Recibido: 31/05/2019

Evaluado: $13 / 06 / 2019$

Versión Final: 01/08/2019 